\title{
CRESCIMENTO INDUSTRIAL NA REGIÃO DE ARARAQUARA E SÃO CARLOS NAS PRIMEIRAS DÉCADAS DO SECULO XX
}

\author{
Helena Carvalho De Lorenzo ${ }^{1}$ \\ Larissa Carmelengo Dias Gomes \\ Vera Mariza Henriques de Miranda Costa. ${ }^{2}$
}

RESUMO

Este artigo descreve e analisa a formação das primeiras atividades manufatureiras e o crescimento industrial na região de Araraquara e São Carlos no início do século XX. Mostra que a partir do desenvolvimento da economia cafeeira na região criaram-se as condições iniciais para o aparecimento de uma diversificada atividade de transformação industrial de bens para o consumo local e regional que pôde sobreviver enquanto prevaleceram as condições para o seu funcionamento e reprodução. Contudo, as mudanças na economia paulista, após a crise de 1929, trouxeram profundas modificações nos rumos da indústria na região. São tomados como referência estudos clássicos sobre a origem da indústria em São Paulo. Do ponto de vista metodológico a pesquisa que deu origem ao presente estudo foi de natureza exploratória e investigativa de fontes primária e secundária. As considerações finais apontam para a natureza cíclica das atividades produtivas regionais, para mudanças no ciclo produtivo da região a partir dos anos 30, e para as razões da sobrevivência de algumas empresas que conseguiram superar as dificuldades iniciais e até o século XXI participam da estrutura produtiva regional.

Palavras-Chave: Crescimento industrial; origem da indústria em São Paulo; café e indústria em São Paulo; origem de indústria na região Araraquara-São Carlos. 


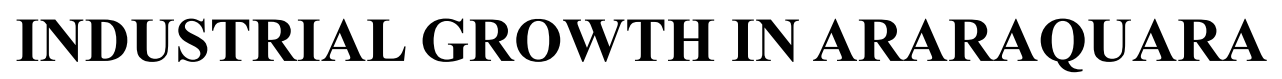

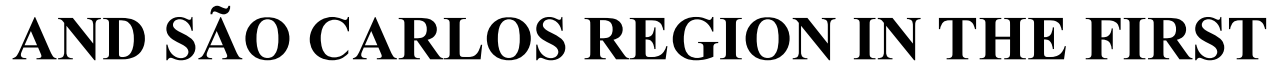 DECADES OF THE TWENTIETH CENTURY}

\section{ABSTRACT}

This article describes and analyzes the formation of the first manufacturing activities and the industrial growth in Araraquara and São Carlos region in the early twentieth century. It shows that from the development of the coffee economy in the region, were created the initial conditions for the emergence of a variety of industrial transformation activities of goods for local and regional consumption that could survive while the conditions for its operation and reproduction prevailed. However, changes in the state economy after the 1929 crisis brought deep changes in industry course in the region. Classic studies on the industry origin in São Paulo are taken as reference. From a methodological point of view the research that led to this study had an exploratory and investigative nature of primary and secondary sources. The conclusions point to the cyclical nature of regional productive activities, to changes in the production cycle of the region from the $30 \mathrm{~s}$, and to the reasons for the survival of some companies that have managed to overcome the initial difficulties and till the XXI century are part of the regional productive structure.

Keywords: industrial growth; industry origin in São Paulo; coffee and industry in São Paulo; industry origin in Araraquara- São Carlos region.

\section{INTRODUÇÃO}

O presente artigo apresenta de forma sintética parte dos resultados de uma pesquisa realizada entre os anos de 1974 e 1978, referentes ao estudo da origem e desenvolvimento da indústria na região Araraquara-São Carlos. A investigação buscou Araraquara-São Carlos. A investigação buscou transformação industrial que surgiram na região no contexto da economia cafeeira e no imediato pós-crise de 1929.

Um dos elementos motivadores para estudar a região foi a tentativa de aplicar os "supostos" ou "teorias" sobre a origem da indústria em São Paulo e no Brasil para explicar o crescimento industria da região. Mais voltados para a compreensão dos processos mais gerais do desenvolvimento inicial da indústria, essas "teorias" estão voltadas a aspectos mais amplos e não tratam de especificidades regionais. Se as regiões brasileiras, no que se refere à origem da indústria, sabidamente apresentam enormes diferenças entre si, isso também é verdadeiro para recortes territoriais menores dentro do estado de São Paulo. E o caso da região em questão na qual as especificidades locais apontavam para uma diversidade de situações e riqueza de informações que apenas em um contexto menor poderiam ser observadas e contribuir para a compreensão de dinâmicas produtivas especifica do território em questão. Nesta direção um dos focos de interesse da pesquisa foi a tentativa de identificação da diversificada atividade manufatureira de pequeno porte que surgiu no bojo da economia cafeeira nos primeiros anos do século XX criando importante mercado local e regional. Diferentemente de outras regiões mais a oeste do estado, nas quais o café foi atividade predominante, a região em estudo apresentou uma diversificada ativid produtiva, não apenas na agricultura, mas também nas manufaturas. Contudo, após a crise cafeeira de 1929, a maior parte dessas atividades desapareceu, deixando poucos vestígios. Assim, as manufaturas surgidas na época cafeeira não foram o embrião para o futuro perfil produtivo da região, como em outras regiões mais próximas à capital do estado. O artigo busca entender esse período da história da indústria na região respondendo as perguntas: como e sob que condições se desenvolveram as a diversificação produtiva nos primeiros anos do desenvolvimento da região? Quais as marcas dessas atividades para o futuro produtivo da região?

Deve ser destacado que o artigo não tem a pretensão de apresentar uma história do desenvolvimento econômico da região e está mais voltadi limitada do desenvolvimento econômico e não aborda a complexidade das relações em geral envolvidas nesses processos, mas descreve aspectos voltados à história da indústria relacionados à formação do mercado local. Pretende mostrar que harmônica ou linear, e que o crescimento industrial no período cafeeiro foi carregado de conflitos e contradições, que revelam a natureza capitalista dessas relações

$\mathrm{O}$ artigo está organizado em oito itens, incluindo esta introdução e as considerações finais. O segundo item apresenta a metodologia utilizada para a realização da pesquisa, a delimitação da região em estudo, bem como as fontes secundárias e, principalmente, as fontes primárias utilizadas. O terceiro sintetiza os principais estudos sobre a origem da industria em São Paulo, com vistas a estabelece referências teóricas e balizadoras para a análise apresentada. O quarto descreve as primeiras manufaturas surgidas com a chegada do café e pela presença das antigas fazendas mistas na região. O quinto item descreve o crescimento industria $\mathrm{XX}$. O sexto descreve o desenvolvimento diversificaça das manufaturas na decada os fatores que a incentivaram. de 1920 e os fatores que a incentivaram. O impacto da crise de 1929 e o fim do crescimento industrial na região estão apresentados no item 
artigo analisa as especificidades da região frente aos supostos teóricos e históricos utilizados como referenciais.

\section{METODOLOGIA}

Originalmente, a intensão da pesquisa era a de estudar o processo de formação da atividade industrial no município de Araraquara. Entretanto, na medida em que a pesquisa mostrou ser necessário analisar os dados coletados sobre a evolução industrial no município em um "contexto regional", defrontou-se com a necessidade de ter que delimitar uma região.

Uma primeira tentativa foi a de utilização da Região Administrativa de Ribeirão Preto Sub-Região de Araraquara. Nesse caso a própria natureza do trabalho impunha a necessidade de trabalhar com dados de censos econômicos considerando a própria evolução das atividades industriais de cada um dos municípios, surgindo, então, um problema decorrente das questões de desmembramentos de distritos na constituição de novos municípios. Como se sabe, as informações contidas nos censos econômicos nem sempre são fornecidas em nível de distritos; assim sendo, torna-se impossível visualizar e fazer comparações quando um distrito se desagregava e passava a compor um novo município.

Na ocasião (1978) foi delimitada como universo de pesquisa a Microrregião Homogênea 242 - área delimitada pelo IBGE ${ }^{3}$, localizada em área central do estado de São Paulo abrangendo os seguintes municípios: Araraquara, Américo Brasiliense, Boa Esperança do Sul, Borborema, Descalvado, Dobrada, Dourado, Ibaté, Ibitinga, Itápolis, Matão, Nova Europa, Ribeirão Bonito, Rincão, Santa Lucia, São Carlos e Tabatinga.

A escolha da Microrregião Homogênea 242 fo estratégica pela possibilidade de agrupamento de 3 3- Atualmente não existe mais esta delimitacão territorial. Naquela área encontrava-se incluída na Região Administrativa de Ribeirão
Preto (6 a. Região Administrativa de São Paulo) e abrange as sub-regiōes de 1 eros 7 (com exceção do municííio de Cândido Rodrigues) $\mathrm{e} 8$, respectivamente sub-regĩos de Araraquara e São Carlos.

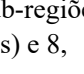

68 Revista Uniara

Lowiara

municípios e pela construção de séries históricas. A possibilidade de agrupamento de seus municípios ocorreu, através da utilização dos critérios de delimitação jurídico-administrativo, indicados pelo Censo Demográfico de 1920. Tal procedimento viabilizou-se uma vez que, mesmo desmembrados, em suas origens, os municípios naépoca da realização da pesquisa pertenciam à Micro- Região 242. Além do mais, considerando-se que os desmembramentos ocorridos na área não se processaram a partir do efetivo desenvolvimento de antigos distritos, mas simplesmente respondendo à "pressões locais" que reivindicaram para eles a posição de município, a atitude tomada não representaria fonte de viés na análise. Assim sendo, os municípios foram reagrupados da seguinte forma: 1-Município de Araraquara, englobando os atuais municípios de o municipio de Rincão, o de Santa Lúcia e o de Américo Brasiliense ( os três últimos desmembrados, respectivamente, em 1948, 1958 e 1964); 2-Município de Boa Esperança do Sul 3-Município de Descalvado; 4-Município de Dourado; 5-Município de Ibitinga, englobando os atuais municípios de Ibitinga, Tabatinga Nova Europa ( os dois desmembrados em 1925 e 1953, respectivamente); 6-Município de Itápolis, englobando os municípios de Itápolis e Borborema ( este último desmembrado em 1925); 7-Município de Matão, englobando os municípios de Matão

e Dobrada (este último desmembrado de Matão em 1964); 8- Município de Ribeirão Bonito: e 9Município de São Carlos, englobando os municípios de São Carlos e Ibaté (o último desmembrado em 1956). Dessa forma, sempre que no decorrer do trabalho nos referirmos, por exemplo, ao município de Araraquara, estamos entendendo o município de acordo com seu estatuto legal delimitado pelo Censo Demográfico de 1920, ou seja, os atuais municípios de Araraquara, Américo Brasiliense, Santa Lucia e Rincão.

Em decorrência desse tratamento foi possível construir séries de informações, sobretudo econômicas e demográficas, a partir das quais pudemos verificar que os municípios de São Carlos e Araraquara se destacam no conjunto da região, sob vários aspectos. No que diz respeito à sua formação histórica são os núcleos mais antigos e que, portanto, passaram por todas as fases da evolução da região (Microrregião 242). No que diz respeito à implantação de atividades industriais, na medida em que apresentam maior diversificação medida em que apresentam maior diversificação
industrial, em termos da região, podem ser tomados como representativos do conjunto; além do mais, durante o todo período analisado destacam-se sobre os demais que compõem a referida microrregiã no que se refere: à sua participação no valor da produção industrial; à presença de um maior número de empresas industriais; e à absorção de um maior número de pessoal ocupado na indústria. Por essas razões, optamos por definir como universo de pesquisa a Microrregião 242 e analisar em profundidade os municípios de São Carlos e Araraquara. Em nosso estudo, a Microrregião Homogênea 242 passou a ser denominada "Região de Araraquara e São Carlos".

No contexto de Microrregião Homogênea 242, o estudo teve por objetivo a análise em profundidade de origem da formação e do crescimento industrial dos municípios de Araraquara e São Carlos, principais municípios da região

Para a coleta dos dados de pesquisa tomou-se como base um conjunto de documentos e dados obtidos nos arquivos das Prefeituras e das Câmaras Municipais de Araraquara e de São Carlos, particularmente nos livros de Leis Municipais e nos livros de Registro de Impostos sobre Atividades de Indústria e Profissões, para os anos de 1900 a 1940. Outras informações obtidas em material não catalogado, nos Arquivos do Museu Voluntários da Pátria de Araraquara foram uma importante fonte de pesquisa. Trata-se de correspondência enviada e recebida pelos Prefeitos do Município de Araraquara, nos anos de 1900 a 1940. Essas indicações estão registradas no texto como: Correspondência dos Prefeitos. Arquivos Museu Voluntários da Pátria, Araraquara, 1900-1940.

Também foram consultados os Anuário Estatísticos de São Paulo: Estatística Econômica e
Financeira. Vol. II, para os anos de 1907, 1908,1909, 1916 e 1918, os Censos industriais de 1907 e 1919 , 1940 e as Estatísticas Industriais de 1928 e 1937, obtidas no Departamento de Estatísticas do Estado de São Paulo

Finalmente, foram realizadas algumas entrevistas com alguns empresários locais e pessoas envolvidas com a história da indústria na região.

\section{Pressupostos teóricos e históricos}

Os principais estudos sobre a origem da indústria em São Paulo apoiam-se principalmente na concepção de Celso Furtado que destaca a importância das exportações para a formação da industria e ressalta a importância da expansão industrial no São Paulo. Esse crescimento ocorrido nesta etapa da industrialização induzida pela expansão das exportações, assume a forma de adição de novas unidades de produção, similares às pré-existentes. (FURTADO, 1966). Também considera que a indústria que se desenvolveu durante 0 auge exportador não pode ser considerada como um processo de industrialização propriamente dito, qual seja, o da constituição de um setor capaz de gerar sua própria demanda, mas sim atende a uma demanda pré-existente e pode ser definido como um período de crescimento industrial.

Com algumas diferenças teóricas e metodológicas Cano(1975), Dean (1971)e Silva (1973), aprofundam os estudos sobre a industrialização de São Paulo e apontam para a importância do desenvolvimento da economia exportadora cafeeira como responsável pela criação inicial das condições de formação da indústria

Segundo Cano (1975), as raízes da formação industrial no estado de São Paulo remontam ao início do século XX, quando a expansão da atividade cafeeira, determinada pelo ritmo de acumulação de capital na lavoura, deu origem ao econômicas integradas e inter-relacionadas, 
complexo cafeeiro de São Paulo, que envolvia, além do café, o desenvolvimento de outras atividade tais como ferrovia, imigração, comércio e também atividades industriais. A medida que o complexo cafeeiro de São Paulo se ampliava, novas áreas iam sendo incorporadas e também se ampliavam os estímulos ao aparecimento da atividade industrial. (CANO, 1975)

Como mostra Cano (1975) o acelerado e diversificado crescimento da economia paulista, de 1886 até 1930 , visto em todas as suas manifestações: expansão da oferta de mão de obra, expansão ferroviária, desenvolvimento da agricultura produtora de alimentos e matérias primas, desenvolvimento urbano e aspectos a ele relacionados, a atividades comerciais e de serviços, atividades bancárias e industriais, etc. decorreu, em última instância, da acumulação de capita possibilitada pela expansão da principal atividade do complexo, o café, e das transformações ocorrida nas relações de produção a partir da introdução do trabalho assalariado. A atividade industria que se desenvolveu em São Paulo, até 1930 esteve subordinada à dinâmica de acumulação do capital cafeeiro e foi, no decorrer desse processo, transformando-se em seu principal componente.

Já segundo Dean (1966) a origem da indústria em São Paulo é entendida como decorrente de duas variáveis: as relações externas que deram origem às condições internas de mercado e a habilidade dos primeiros empresários paulistas que souberam e tiveram condições de captar e conduzi adequadamente as oportunidades de mercado. Pelo prisma de Dean (1966) o processo de acumulação de capital, que permitiu a passagem de uma economia agrícola escravista para uma economia industrial, esteve estritamente ligado à capacidade e habilidade do empresário.

Sergio Silva (1976) em seu clássico estudo sobre a expansão cafeeira e as origens da indústria no Brasil, apresenta uma importante contribuição em uma linha bastante diversa dos trabalho anteriores: embora o desenvolvimento da indústria nascente esteja relacionado ao avanço da economia cafeeira e ao crescimento do setor exportador, o autor destaca a natureza contraditória das relações entre café e indústria de modo que, ao mesmo tempo em que surgem incentivos também surgem obstáculos, analisados como contradições próprias do desenvolvimento do capitalismo

Mesmo identificando obstáculos e incentivos distintos nas relações entre café e indústria como explicativos dessas relações, os autores mencionados concordam que no estado de São Paulo três principais segmentos da indústria de transformação se desenvolveram intrinsecamente ligados ao café O primeiro corresponde à fabricação de máquinas e implementos para a agricultura, e em particular para o beneficiamento do café. Esse grupo, ao diminuir os custos da produção e aumentar a produtividade, ampliava os lucros, introduzia nova tecnologia, e ampliava os excedentes do complexo. $\mathrm{O}$ segundo grupo refere-se à produção de sacaria de juta para a embalagem do café, muito embora não se tenha constituído em uma atividade muito redutora de custos (uma vez que seu preço era ditado pelas margens de proteção tarifária), ainda assim era lucrativo aos industriais e ampliava as oportunidades de inversão no complexo. O terceiro grupo compreende os demais subsetores industriais, que nessa etapa de desenvolvimento correspondem à produção de bens de consumo corrente. Esse grupo tem a importante função de manutenção de força de trabalho. Naturalmente, a participação desses três segmentos na indústria paulista ocorreu gradativamente. Tendo-se iniciado a partir da produção de bens mais simples para o consumo tendeu, à medida que se ampliava o complexo, à elaboração de bens de produção. (CANO, 1975)

A partir desses recortes teóricos, o artigo busca analisar as especificidades do crescimento industrial na região como um processo dinâmico e histórico, e fortemente influenciado pela forma como foi se constituindo o mercado local e regional.

As primeiras manufaturas na

região de Araraquara e São Carlos
Na região de Araraquara e São Carlos as primeiras atividades industriais, intrinsecamente vinculadas ao predomínio da economia cafeeira estavam ligadas ao terceiro grupo, ou seja, produção de bens de consumo corrente. Muito embora, desde meados do século passado, ja existissem algumas atividades manufatureiras e de transformação, estas eram pouco significativas e refletiam o período de produção para subsistência em que a região viveu antes da consolidação da lavoura do café. Fundados antes da chegada do café na região (1817 e 1884), nos municípios de Araraquara e São Carlos já existiam desde o início do século XVIII "fazendas mistas", nas quais se produziam diversos produtos de subsistência: fabrico do queijo, açúcar, aguardente e farinha de milho. (CASALECCHI, 1973). Este fato foi um importante fator para o posterior desenvolvimento de algumas agroindústrias de beneficiamento e da pequena indústria de bens de consumo que se desenvolveu no auge cafeeiro.

Os verdadeiros estímulos ao aparecimento das manufaturas surgiram no final do século XIX com a chegada da lavoura cafeeira na área e sua rápida integração ao complexo cafeeiro de São Paulo. integração ao complexo cafeeiro de São Paulo. máquinas na região datam dos fins do século XIX eram máquinas de beneficiamento de café localizadas nas próprias fazendas de café. No município de Araraquara, em 1880, foi montada, na Fazenda São Luís, a primeira mento de cafe. Em 1886, foi instalad na Fazenda Chibarro outra máquina a vapor $\mathrm{Na}$ fazenda Santa Isabel, que teria sido uma das primeiras fazendas de café formadas no município de Araraquara foram montadas em 1892 quatro máquinas movidas a vapor. (LORENZO, 1979)

Ainda no final do século XIX começaram a surgir as primeiras empresas no meio urbano: 3 oficinas mecânicas, 2 mercearias, 6 fabricas de pão e macarrão, 1 fábrica de cerveja e gasosa e 2 alfaiatarias. Essas primeiras empresas se configuravam como pequenos artesanatos, tinham um caráter quase doméstico, montadas nas próprias residências, que utilizavam equipamentos muito rústicos. (LORENZO, 1979)

O início da diversificação

manufatureira: o beneficiamento do café e demais atividades agrícolas

e a pecuária (1900-1920)

Ao longo das duas primeiras décadas do século XX surgem e se diversificam as primeiras manufaturas na região. A expansão do meio urbano foi importante para a consolidação do beneficiamento de café. A população da região que em 1880 era de aproximadamente 4.679 habitantes em 1900 elevou-se para 27.729. (CORREA. A.M.M. 1963)

Também novos beneficiamentos de café e cereais começam a ser instalados no meio urbano, indicando valorização econômica deste espaço que aos poucos tornavam-se tão importante quanto o espaço rural. Em 1905 foram instaladas duas máquinas de beneficiamentos de café em Araraquara e três em São Carlos. Nesse mesmo ano foi instalada em Araraquara a primeira máquina para o beneficiamento de arroz. (LORENZO, 1979) Contudo, essas manufaturas eram atividades vidades de benefícios de cereais, surgidas nessa época, segundo Szmerecsanyi (1977), dentre as atividades agroindustriais produtoras de alimento, por estarem ligadas diretamente às atividades do setor agropecuário, constituem modalidade elementar na elaboracão industrial de produtos alimenticios. Por essa razão não podem ser rigorosam

Outro fator importante para o desenvolvimento das manufaturas no meio urbano foi a chegada da energia elétrica na região, em 1907. Em 1910 já existiam 16 estabelecimentos para o beneficiamentos de café em Araraquara e $9 \mathrm{em}$ São Carlos. Entre 1910 e 1920 foram instalados mais 3 estabelecimentos de beneficiamento, atingindo, portanto, um total de 28 máquinas. Essa 
expansão também foi reforçada pelo interesse dos fazendeiros, que já possuíam máquinas em suas fazendas, em se transferirem-se para a cidade para beneficiar cafés de pequenos produtores, ampliando assim seus negócios (LORENZO,1997).

Entre 1910 e 1920 o interesse dos cafeicultores pelo setor de beneficiamento ficou definido, sendo esses proprietários de 16 máquinas em Araraquara. No caso do município de Araraquara a procedência dos empresários industriais pode ser verificada: a) Em primeiro lugar, porque dispúnhamos de listas com os nomes dos proprietários de empresas industriais, dados por nós obtidos quando do levantamento realizado junto à Prefeitura nos livros de Pagamento de Impostos sobre Indústria e Profissões. b). Esta lista pode ser comparada com outra, também obtida, nos Pedidos de Alvarás para funcionamento de empresas, fonte na qual constavam os nomes dos proprietários de fazendas de café do Município de Araraquara. Esta última lista foi o resultado de um levantamento realizado, e a nós cedido, por José Enio Casalecchi nos livros de Registro de Impostos sobre Café. Além dessas fontes formais, nos casos de dúvida, recorríamos à memória de antigos funcionários da Prefeitura Municipal de Araraquara. Dessa forma, através dessas comparações, verificamos em quais atividades, e quantos eram os fazendeiros de café presentes na atividade industrial.

O caso da fabricação do açúcar na região merece uma consideração especial por seu aspecto cíclico. Tendo-se desenvolvido na região desde o início do século XIX, como um prolongamento da produção de cana da região de Piracicaba, quando da chegada da lavoura do café foi parcialmente substituída por aquele produto, por iniciativa dos próprios proprietários de engenhos.

Tal fato deveu-se às melhores perspectivas de lucro na atividade cafeeira. Entre os anos finais do século XIX até 1910 houve redução da atividade canavieira. Consequentemente, dos antigos engenhos que naquela época existiam no município de Araraquara, apenas um permaneceu em funcionamento (CORREA 1968).

Entre 1910 a 1920 seis antigos engenhos foram reativados. As razões da reativação da lavoura da cana na região, após 1910, certamente estão associadas ao desenvolvimento dessa atividade no conjunto da economia. Para o conjunto do Estado, sabe-se que essa atividade vinha de um longo declínio. Tendo problemas de preços e condições ditadas pela demanda externa, a atividade açucareira ainda dependia de um alto investimento em máquinas e equipamentos. Na década de 1900 a 1910, as exportações brasileiras foram reduzidas à metade do total do que fora exportado de 1840 a 1900 (CANO, 1975). Entretanto, no período de 1916 a 1920 os preços do açúcar tiveram uma razoável recuperação: triplicaram em relação aos preços vigentes de 1880 a 1911. Apesar de a produção paulista, como um todo, não te aumentado, o estímulo decorrente da elevaça , café da regro, particularmente dois fazendeiros, proprietários de terras no município de Araraquara que optaram por adquirir novas terras para o cultivo do café em outras regiões mais a oeste e ampliar a cultura de cana, nas novas áreas. Naquela ocasião foram instalados dois engenhos, nas fazendas, Santa Helena e Santa Isabel, em Araraquara. Por volta de 1926, esses engenhos foram fechados. Foi nessa época que a praga do mosaico, que devastou grande parte dos canaviais paulista, atingiu a região. Tal fato, bem como o incremento dessa atividade no Nordeste, levou à desativação da de açúcar no Estado de São Paulo (SUZIGAN, VILLELA, 1973; PINA, 1972). Os proprietários, desestimulados pelos preços baixos fecharam os engenhos. Dessa forma, a atividade canavieira tendo passado por fase de evolução, novamente regrediu ao mesmo estágio em que se encontrava em 1910. No ano de 1930, havia apenas um engenho em funcionamento na região. (LORENZO, 1979)

Outro exemplo de diversificação produtiva na região foi a indústria de beneficiamento e pasteurização do leite. Diferentemente de outras regiões que tinham foco no café, na região de Araraquara a pecuária e a lavoura de cana de açúcar tinham sido desde meados do século XIX as atividades responsáveis pela ocupação do território Com a chegada e a consolidação da lavoura do café, a pecuária perdeu a sua importância, tendo passado para um segundo plano. Entretanto, essa atividade não desapareceu inteiramente e continuou a ser realizada em pequenas áreas, relativamente montanhosas e impróprias ao cultivo do café, localizada em áreas próximas de Araraquara e São Carlos.

A instalação de uma usina de pasteurização de leite em 1911, no município de Araraquara, foi iniciativa de um grupo de fazendeiros que, liderados por Bento de Abreu Sampaio Vidal, importante empresário da região, mandaram buscar na Argentin equipamentos que garantissem a conservação do leite. Esta empresa foi importante, tanto para os grandes fazendeiros, que viam na pecuária uma possibilidade alternativa de investimentos, quanto para os pequenos proprietários e sitiantes, para os quais a atividade cafeeira não era possível por suas possibilidades econômicas restritas e pelas instabilidades da situação econômico-financeira da lavoura.

$\mathrm{O}$ estudo apurou que na região a atividade cafeeira não foi a única base do desenvolvimento local e os próprios cafeicultores da região estavam atentos para a importância da diversificação das suas atividades; as quais, entretanto, não chegaram a competir com o café. Tratava-se de uma busca de alternativas para as crises que frequentemente preocupavam os fazendeiros locais. A correspondência de 1928, entre Bento de Abreu, um dos proprietários da empresa e Plínio de Carvalho, (então prefeito de Araraquara), confirma a interpretação proposta e evidencia o tipo de visão dos proprietários e a importância da manutenção e ampliação da atividade pecuária para a região.

“Em Buenos Aires os jornais entendem que esse serviço deve ser da municipalidade.(...). poderia ficar fiadora do empréstimo. A situaçãó a seguinte: atualmente ocopital companhia, contando com as minhas ações, é quase toda da Câmara. "Raythe" o maior interessado no êxito entra com 40 contos. Ficamos com o capital de 105 contos e com uma divida de 150 contos ...... . A renda no ano passado foi de 43 contos liquidos, incluindo o gelo que se comprou. Com a empréstimo será pago em anos contos. O ficrá dono sora pago en anos e a Cânara “Meu ponto de vista ñ ć esse do dineiro Meu ponto de vis hó esse do dinheiro Arara imitará a noss lei. "Por um lodo, tero que ramento do consumo de leite, buciado a saúde da populaça e por outro lado a criação de vacas leiteiras que além de ser uma riqueza aumentará as oportunide dos nossos fazendeiros nos difíceis dias de Thalme" (CÂMARA MUNICIPAL DE ARARAQUARA, 1928, caixa 28).

De forma semelhante, o comportamento dos overnantes dos municípios de Araraquara e São Carlos evidenciaram preocupações com o desempenho da atividade cafeeira e procuraram estimular o desenvolvimento de outras atividades industriais, através da elaboração de projetos que favoreciam, em especial, o desenvolvimento da ndústria têxtil, do algodão, da seda e do linho. Leis de estímulo, votadas pelas Câmaras Municipais de Araraquara e de São Carlos, composta quase que totalmente por indivíduos fortes vínculos entre o café e a indústria nascente. Várias leis de incentivo à diversificação produtiva foram sancionadas, entre 1908 e 1923, período em que a lavoura cafeeira enfrentou diversas crises. Seis leis ofereciam apoio aos que se interessassem pelo plantio do algodão e aos que se dispusesse a instalar fábricas de tecidos. A lei municipal de Araraquara ${ }^{\circ} 140$ de 20 de janeiro de 1908 aprovou o projeto que estabelecia para o município: “ Art. $1^{\circ}$ - É isento de qualquer imposto, inclusive predial, água e esgoto, por espaço de dez anos, a fábrica de tecidos de algodão que se montar nesta cidade. Câmara contribuirá anualmente com a quantia de 
dez contos de réis, por espaço de cinco anos. Art. $3^{\circ}$ - Para gozar dos favores dessa lei, a fábrica não poderá ter menos de 25 teares. Art. $4^{\circ}$ - Se para a montagem da fábrica for organizada a sociedade por ações e estas não encontrarem tomadores que perfaçam a importância de capital preestabelecido e a realizar, a Câmara subscreverá ações para realização deste capital até cem contos de réis. Art. $-5^{\circ}$ São autorizadas as operações de crédito para o correr dos fins desta lei" (CÂMARA MUNICIPAL DE ARARAQUARA, 1908 - 1929).

Incentivos fiscais eram demandados po fazendeiros da região interessados em investir em outros setores. Em 1910, Carlos Batista Magalhães, importante fazendeiro da região dispôs-se a monta uma fábrica de tecidos de algodão; esta, entretanto, enfrentou a falta de matéria prima. Novamente a Câmara de Araraquara fez apelo aos plantadores, porque julgava que a instalação de uma indústria têxtil era indício de prosperidade. E ainda, por julgar que as vantagens oferecidas não teriam sido suficientes - o que justificaria o insucesso do empreendimento - propôs doação de terreno na cidade e facilidades na obtenção de água, luz e calçamento (LORENZO, 1979).

Em função desses novos estímulos, várias tentativas foram realizadas. Contudo, não tiveram vida longa. Em 1911, a Prefeitura de Araraquara efetuou um acordo com Frederico Abranches, para a montagem de uma indústria de fiação, que não chegou a ser montada. Em 1918, surgiu uma firma interessada (Monteiro e Cia), na montagem de uma fábrica de fiação e tecidos. Em 1923, outra firma (Diógenes de Arruda Castanho e Fenício Formasari) interessou-se pela montagem de uma fiação e solicitou à Câmara de Araraquara o auxílio de 100:000\$000 em ações da Companhia, doação de terreno e isenção dos impostos por 10 anos (LORENZO 1979).

Em São Carlos, a primeira indústria de fiação e tecelagem de algodão, para a produção de sacos para embalagem do café, Fiação e Tecelagem Magdalena, foi montada em 1911, de propriedade de um fazendeiro de café. Mas as tentativas não atingiram o efeito desejado. Muito embora a presença de estímulos tenha ocorrido nas fases de crises da lavoura cafeeira, a recuperação do café desviava novamente a atenção para essa atividade, evidentemente muito mais compensadora (LORENZO 1979).

A partir dos primeiros anos do século $\mathrm{XX}$ a ferrovia, presente no território desde o final do século XIX, foi importante fator na qualificação da força de trabalho e na integração regional. Formou mecânicos, que posteriormente se destacariam como empresários industriais, e aproximou os municípios da região, até então isolados.

A ferrovia também foi importante incentivo à diversificação da produção manufatureira como as fábricas de dormentes e marcenarias que oficina da Estrada de Ferro de Araraquara construía vagões tanto para o transporte de passageiros como o de cargas. Também surgiram oficinas mecânicas e fundições pela necessidade de reparos ou construções de peças para as máquinas de beneficiamento do café e pela chegada da ferrovia. Nestas atividades em geral se destacava a figura do imigrante como o empresário. Em 1911 foi instalada em Araraquara uma fábrica de cilindros "Ortiz" de propriedades de imigrantes italianos, tendo sobrevivido até 1928. Antônio Blundi, outro imigrante italiano, inventou um descaroçado manejo, graduacão matemática e processava 100 arrobas por hora". Este mesmo imigrante teria solicitado à Prefeitura um empréstimo para produzir localmente a máquina e, como não conseguiu obtêlo, acabou por vender sua patente para a Companhia Mac Hardy, firma inglesa que comercializava máquinas agrícolas na região (LORENZO 1979).

A fábrica de dormentes, localizada no município de São Carlos, de propriedade de imigrante que chegou à região para o trabalho de construção de ferrovia, foi montada em 1911 em função das necessidades requeridas de reparo e construção foi reduzida a um depósito de madeiras que ainda existe no município de São Carlos.

No município de São Carlos as relações entre a expansão cafeeira e o desenvolvimento da indústria pode também ser percebida tanto pelo interesse de fazendeiros de café em incentivar e mesmo investi na indústria, quanto pela participação de imigrantes, que se dirigem à região em função da presença dessa na lavoura.

Um discurso proferido na Câmara Municipal de São Carlos por um vereador - João Angelo Aprattitambém fazendeiro de café, em 1911, revela o interesse dos fazendeiros pela atividade industrial:

"As Câmaras Municipais, autônomas como elas são, podem conseguir muitas coisas úteis, destinando verbas aptas para coisas uteis, destinando verbas aptas para aqui por demais escasseia. Seja este ponto principal, a miragem mais santa, porque estando a lavoura em completa decadência, urge dar uma vida nova ao nosso município É necessário fazer surgir fábricas, oficina em cujo seio possa ganhar o pão, centenas centenas de pessoas, as quais com o concurso dos seus trabalhos dariam sempre maiores incrementos a esta cidade. Tomemos de exemplo Piracicaba, para não citar outras cidades, que progridem exclusivamente à custa das suas indústrias; vimos que seu povo satisfeito, quer estrangeiro, quer nacional, ali permanecem por muitos e muitos anos. Esperamos, portanto que a nova edilidade, prosseguindo o caminho do progresso, cogita

Tabela 1: População presente nos municípios componentes da designada Micro - Região em 1920.

\begin{tabular}{l|l|l|l|l}
\hline Municípios & Distritos & Brasileiros & Estrangeiros & Total Geral \\
\hline (A) Araraquara & Araraquara & 22.971 & 7.609 & 30.583 \\
\hline & Santa Lúcia & 3.261 & 1.254 & 4.515 \\
\hline & Rincão & 5.857 & 1.929 & 7.786 \\
\hline & N. Pauliceia & 3.558 & 1.677 & 5.235 \\
\hline & Total & 35.647 & 12.469 & 48.119 \\
\hline & São Carlos & 31.994 & 10.253 & 42.282 \\
\hline & Ibaté & 5.695 & 1.957 & 7.659 \\
\hline & Sta. Eudóxia & 3.025 & 1.077 & 4.284 \\
\hline & Total & 40.894 & 13.287 & 54.225 \\
\hline & 152.902 & 51.512 & 204.688 \\
\hline & \multicolumn{4}{|l}{} \\
\hline
\end{tabular}

Fonte: IBGE. Censo de 1920. os mercados regionais. assim como tem cogitado de outras coisas, de introduzir mais estas modernas inovações. São estes os melhoramentos que servem (DAMIANO, 1954 4 46).

A participação de fazendeiros de café na ndústria em São Carlos ocorreu em diversos outros segmentos produtivos. Leonardo Botelho, além de ser fazendeiro de café e possuir armazém de ferragens, de tinta e óleos, também era proprietário de uma fábrica de móveis, de ferraria, serralheria e fundição, de oficinas de marcenaria e carpintaria. Em 1911 adquiriu de um imigrante da região a patente de um Ventilador Duplo para preparar o café em coco para ser descascado e passou a produzi-lo em sua fundição. Também produzia a "Fornalha Econômica Paulista" para queima da palha de cafe (LORENZO, 1979).

\section{Diversificação e expansão das}

manufaturas nos anos 1920: 0

crescimento populacional, os incentivos

fiscais e a presença de imigrantes

O aumento da população na área foi essencial para a formação do mercado local e regional. Em 1920, Araraquara e São Carlos faziam parte dos mais de 30.000 habitantes. A forte presença de imigrantes fortalecia 
No inicio da década de 1920 a Câmara Municipal de Araraquara se empenhou em incentivar a produção do algodão, visando a sua industrialização. Mas somente após 1925, o algodão começou a se intensificar na região. Entretanto, da pretendida indústria algodoeira, o que se firmou na região foram os estabelecimentos para a fabricação do óleo. Em 1925 foi instalada uma máquina descaroçadora de algodão - Sociedade Anônima Cotonificadora do Brasil, de Araraquara, que foi a primeira a ser instalada no Brasil no gênero e contribuiu para atividade agroindustrial que se firmará posteriormente na região, depois da crise cafeeira de 1929 (LORENZO, 1979).

O mesmo ocorreu com produção da seda do linho, sendo que a Prefeitura de Araraquara prontificou-se a comprar terreno para a manutenção de um estabelecimento de ensino da técnica de fabricação. A criação do bicho da seda, buscada desde 1902 e implantada em 1906, recebeu incentivos por volta de 1925, conforme mostra uma correspondência do Diretor da Estação Sericícola de Barbacena, Minas Gerais, à Câmara Municipal de Araraquara:

"Como sabeis, o governo federal e o dess Estado estão empenhados em dar todo impulso à indústria sérica: o primeiro concede os favores da lei 4.632 de 6 de junho de os fa23. o governo do Este 6 de junho de regulamentou a lei $n^{\circ} 2035$ de 30 de dezemb de 1924 e assignou, posteriormente, contracto com a Sociedade Anonyma Industrial de Seda Nacional, de Campinas, a qual subvenciona fornecer gratuitamente até 500.000 óvulos de bicho da seda e 2500.000 mudas de amoeir bicho da seda e 2.500 .000 mudas de amoeir aos criadores de sirgo...e adquirir dos mesmo toda produção de casulos ao preço minimo de DE ARARAQUARA, 1928, caixas 28 e 29).

Este estímulo surtiu efeito e houve expansão dessa atividade, que culminou com a instalação da referida fiação, em 1920. Entretanto, em 1926 essa unidade desapareceu, e, juntamente com ela, a atividade de criação.

Assim, embora essas atividades contassem com o apoio e os incentivos das autoridades locais, nem todas

se firmaram. As atividades de beneficiamento do café, apesar de se terem mantido durante todo o período, foram se reduzindo numericamente, à medida que o café foi avançando em sua marcha para o este. A indústria de fabricação do açúcar, tendo apresentado uma fase de ascensão, estava naturalmente subordinada ao ritmo da expansão cafeeira; dessa forma, no momento em que, durante os anos da guerra, surgiu uma situação conjuntural favorável, a indústria açucareira pode crescer, entretanto, tendo desaparecido as principais razões que permitiram sua expansão, a produção do açúcarentra em decadência. A indústria de pasteurização do leite, dentre as atividades agroindustriais que se desenvolveram na região durante o predomínio do café, constituiu-se em uma exceção, na medida em que subsistiu durante toda essa fase. Apecuária, na região, conforme já mencionado, tendo tido sua origem antes do aparecimento do café, desenvolveu-se como uma atividade do complexo o cultivo do cufe. Por ão ter quecompetr, de utilização da terra, com a atividade cafeeira, e, ainda por ter um bom mercado local, decorrente do aumento da população na área, a pecuária pôde desenvolverse durante toda a fase da expansão cafeeira dando origem à pequ de pasteurização de leite, também não competindo com o café em termos de lucratividade, representou sempre segunda oportunidade de inversõese, portanto, de novos lucros, os quais, pequenos ou grandes, se somariam aos lucros da atividade cafeeira.

Na década de 1920 o numero de estabelecimentos industriais voltados ao consumo local elevou-se significativamente. Essas atividades, diferentemente das anteriores necessitavam de pouco capital para seu funcionamento e estariam menos vulneráveis às crises que frequentemente abalavam a região e a atividade cafeeira. Os imigrantes contribuíram significativamente na producão manufatureira de bens de consumo menos elaborados que mostravam a tendência à reprodução de seu estilo de vida e ao atendimento de suas necessidades básicas. Firmou-se na região uma diversificada atividade manufatureira, a qual apesar de ter sido constituída por empresas de pequeno porte sobreviveu durante todo o período de predomínio da lavoura cafeeira.
Tabela 2: Atividades manufatureiras na região de Araraquara e São Carlos. (1910, 1920, 1930,1940)

\begin{tabular}{|l|l|l|l|l|}
\hline Atividades & $\mathbf{1 9 1 0}$ & $\mathbf{1 9 2 0}$ & $\mathbf{1 9 3 0}$ & $\mathbf{1 9 4 0}$ \\
\hline Olaria e Fábrica de ladrilhos & 7 & 10 & 15 & 9 \\
\hline Oficina Mecânica e Fundição & 8 & 25 & 41 & 29 \\
\hline Fábrica de máquinas para lavoura & - & - & 1 & - \\
\hline Fábrica de rastelos & - & 1 & 1 & - \\
\hline Fábrica de cabo de arado & - & 1 & 1 & - \\
\hline Fábrica de peneiras & - & 2 & 3 & 1 \\
\hline Fábrica de carroças & - & 2 & 4 & 2 \\
\hline Marcenarias e carpintarias & - & - & 27 & 27 \\
\hline Fábricas de móveis e dormentes & 4 & 22 & 28 & 17 \\
\hline Curtume & 1 & 6 & 18 & 15 \\
\hline Fábrica de velas & 1 & 20 & 2 & 1 \\
\hline Fábrica de adubos & - & 1 & 1 & 1 \\
\hline Fábrica de cola & - & - & 1 & - \\
\hline Fábrica de sabão & - & 12 & 14 & 14 \\
\hline Fábrica de tecidos de algodão & 1 & 1 & 2 & 2 \\
\hline Fábrica de tecidos de seda & - & - & 1 & 1 \\
\hline Fábrica de roupas & - & - & 19 & 24 \\
\hline Fábrica de chapéus & - & - & 2 & - \\
\hline Fábrica de camisas & - & - & 2 & 1 \\
\hline Fábrica de meias & - & 1 & 4 & 1 \\
\hline Fábrica de calçados & - & - & 1 & - \\
\hline Fábrica de tamancos & - & 1 & 2 & 1 \\
\hline Fábrica de doces & - & - & 5 & 4 \\
\hline Beneficiaria de café e cereais & 25 & 27 & 19 & 14 \\
\hline Fábrica de pães e macarrão & 16 & 30 & 25 & 18 \\
\hline Fábrica de salsicha & - & - & 1 & 7 \\
\hline Fábrica de gelo & - & 1 & 1 & 1 \\
\hline Benef. e past. de leite & - & 2 & 1 & 2 \\
\hline Fábrica de cerveja e gasosa & 6 & 15 & 28 & 18 \\
\hline Fábrica de açúcar e álcool & 1 & 9 & 1 & 2 \\
\hline Fábrica de aguardente & 4 & 11 & 14 & 12 \\
\hline Tipografia & - & 36 & 10 & 6 \\
\hline Fábricas de caixa de papelão & - & 4 & 1 & 6 \\
\hline Fábricas de brinquedo & - & 1 & 1 & - \\
\hline Fábricas de pilhas elétricas & - & 1 & 1 & - \\
\hline Fábricas de instrumentos musicais & - & 1 & 1 & - \\
\hline Fábrica de vassouras & - & 1 & 1 & - \\
\hline Fábrica de espelhos & - & 2 & 2 & 1 \\
\hline Fábrica de lápis & - & 1 & - & - \\
\hline Total & $\mathbf{7 4}$ & $\mathbf{2 4 7}$ & $\mathbf{3 0 2}$ & $\mathbf{2 3 7}$ \\
\hline & & & & \\
\hline & & & & \\
\hline & & &
\end{tabular}

Fonte: Livros de Impostos sobre atividade: indústria e profissões. 1901 a 1940. Livros de pedidos de alvará de funcionamento 1901 a 1940. Arquivos das prefeituras municipais de Araraquara e São Carlos. 
Também durante a década de 1920 destacaramse a produção de alguns produtos pouco elaborados para os mercados local e regional. Duas fábricas de meias em Araraquara eram também propriedade de imigrantes. A mais importante, a fábrica de meias "Lupo" começou a funcionar em 1919 na residência de seu proprietário. O trabalho era inicialmente feito pela família. Tratava-se de uma família de relojoeiros e ourives, natural de Strigno, região especializada nessa atividade, localizada na província de Trento, na Itália. A fábrica se iniciou com a importação e compra de máquinas de uma cidade do interior do estado do Rio de Janeiro. Com a habilidade dos proprietários no manejo das máquinas, puderam coloca-las em funcionamento, produzindo meias de algodão para a cidade de Araraquara e vendendo por toda a região através de vendedores ambulantes. Esta empresa sobreviveu a várias crises e até o presente se impõe no mercado nacional de confecções e têxteis (LORENZO, 1979).

Outra fábrica de meias instalou-se em $1921 \mathrm{em}$ Araraquara, e encerrou suas atividades em 1923. Durante o período em que se manteve ativa, a fábrica vendia seus produtos nos municípios de Itápolis, Ibitinga, Matão (LORENZO, 1979).

Doze fábricas de sabão do município de Araraquara eram propriedades de imigrantes. A mais importante foi fundada em 1911, Fábrica de Sabonete Mazieiro, a qual sobreviveu até a segunda metade do século XX. Os principais compradores dessa fábrica de sabão, além do município de Araraquara, eram municípios de Matão, Dobrada, Santa Lúcia e Rincão.

A fábrica de brinquedos, que apareceu no rol das empresas que iniciaram atividades no período aqui analisado, solicitou à Prefeitura de Araraquara o alvará para seu funcionamento em 1919. Era de propriedade de uma família de imigrantes italianos que inicialmente foi residir em uma fazenda da região como colonos. Nas horas de folga as mulheres da família se dedicavam à confecção de bonecas de pau ou de pano ou de massa de papel e cola, as quais eram vendidas no mercado da cidade. Em 1919 teriam sido multados por fiscal rural por estar exercendo indústrias e profissões sem respectivas licenças. A família veio a residi na cidade de Araraquara e instalou na propria residência a fábrica de brinquedos. Em 1925 , além das bonecas - confeccionavam 50 bonecas por semana - construíram um forno e passaram a confeccionar utensílios domésticos de barro. Segundo depoimento de um filho do proprietário na época das festas de Natal, vinham compradores até de Goiás (LORENZO, 1979).

A década de 1920 foi, portanto, particularmente favorável à expansão das manufaturas na região, muitas com a participação de imigrantes na estrutura produtiva manufatureira: de colas e adubos fundadas em 1920, permaneceram em atividade até 1932 , de anil de tintas, de 1920 a 1935 , de malas 1920 à 1932 , de chapéus e enfeites para senhoras, de 1912 a 1925, de camisas de 1925, de espelhos, de 1916 a 1932, de instrumentos musicais (que produzia gaitas e sanfonas), de 1920 à 1935 de lápis, em São Carlos, de 1923 até o presente.

A indústria de alimentos, no entanto, foi a mais ativa dentre as atividades mais diretamente voltadas ao mercado local e regional. Existiam em Araraquara, entre 1920 e 1930, inúmeras fábricas de pães, bolachas, doces, caramelos, dentre as quais uma confeitaria mecânica em 1911. Em 1915 havia 19 fábricas de cerveja. Uma delas, de tinas da fermentação, dois tonéis, uma máquina para fabricação de gasosos, 1 caldeirão, um lote de garrafas, uma carrocinha, 18 cadeiras e outros matérias (LORENZO, 1979).

Um dos estabelecimentos mais importantes dessa época foi a fábrica de gelo instalada em especialmente para atender às necessidades da usina de pasteurização de leite. Para sua instalação a "Gás Motoren Fabrik Deutz" do Rio de Janeiro enviou um engenheiro especializado. A fábrica produzia 1.700 quilos de gelo diariamente. A câmara frigorífica tinha capacidade para 7.000 quilos. A mesma firma, cujo capital era, no ano de 1916, de 20.000\$000 contos, também se dedicava a outras atividades. Era agente para região da Santos e semanalmente vendia 600 quilos de peixe. Também possuía uma torrefaça de café: Café Paulista. (LORENZO, 1979)

No que diz respeito à investigação sobre origem do capital industrial, observou-se na história da indústria na região a forte presença de investimentos diretos de cafeicultores na indústria. Assim, podese afirmar que, tanto direta como indiretamente, $\mathrm{o}$ capital cafeeiro foi responsável pela expansão das manufaturas.

No caso da região, as atividades industriais que se desenvolveram compostas por segmentos industriais simples e, de fato, mais prestadores de serviços de que produtores de bens industriais propriamente ditos, necessitaram de muito pouco capital financeiro e contavam muito mais com o conhecimento das técnicas trazidas pelo principa empresário: o imigrante. Considerando-se que a atividade cafeeira (compreendida desde a produção até a exportação), não gerou os aspectos negativos de concentração de renda e nem excessiva dispersão de seu excedente, pode-se supor que uma parte da renda do café (via pagamento de diversas ordens e especialmente ao trabalho) permanecesse na região e possibilitasse o capital necessário à instalação das empresas de pequeno porte.

$\mathrm{O}$ investimento direto de capital cafeeiro na indústria evidencia o interesse do fazendeiro po essa atividade. Na verdade, a indústria local era extremamente importante para o fazendeiro, a participação de imigrantes para atender parte de suas necessidades de consumo e as necessidades de consumo da mão- de- obra empregada na lavoura liberava capitais cafeeiros para investimentos mais lucrativos (tanto na própria indústria, como no caso da indústria açucareira ou têxtil, quanto para a aquisição e abertura de novas fazendas de café em regiões mais a oeste do estado). O que a história da região sugere é que não havia necessidade de o fazendeiro investir na indústria de bens de consumo para que ela existisse e cumprisse o seu papel como um elemento de sustentação da economia cafeeira. Subordinada, assim, às condições engendradas pelo café, a indústria regional pôde sobreviver enquanto prevaleceram as condições que estimulavam sua presença.

\section{A crise de 1929 e o fim da etapa}

\section{de crescimento industrial na região.}

Com a crise de 1929, a queda dos preços do café e a eclosão de uma crise interna, que desde alguns anos anteriores já se insinuava em decorrência do excessivo aumento da produção paulista e da expansão dos plantios em outros estados, desorganizacão da economia cafeeira teve efeitos não apenas setores da economia, dentre os quais a atividade industrial. (FURTADO, 1966)

A região na década de 1930 passou por forte crise e a desorganização do processo de crescimento industrial que vinha se desenvolvendo desde os primeiros anos do século foi uma consequência. Houve forte redução nas atividades existentes e no número de estabelecimentos (LORENZO, 1979).

O fechamento das empresas se deveu a várias razões, mas quase sempre ligadas às mudanças nas condições de produção criadas pelo mercado cafeeiro. Em primeiro lugar, observa-se nessa epoca o peso da política fiscal local, muito sentida pelos "industriais locais", que responsabilizaram os altos impostos da prefeitura como um fator de fechamento de empresas. Nas correspondências dos Prefeitos de Araraquara localizamos diversas cartas enviadas ao então Prefeito de Araraquara, acusando os altos impostos municipais como responsáveis por "falência" e fechamento de empresas. Dentre essas, destacamos uma carta enviada por um "industrial" ao Intendente Municipal de Araraquara no ano de 1932:

"Com o fim de obter uma redução no imposto sobre minha machina de moer casca para uso curtume me permito externar a $\mathrm{V}^{0}$. $\mathrm{S}^{\mathrm{o}}$. diversos "Considerandum": Iniciei minha 
indústria sem machinario algum remetendo casca, ( como muitos fazem) no mercado de São Paulo sem ter que pagar imposto algum. Ao fim de gozar da capacidade dos vagões cousa impossivel com casca em canna, me decidi servime de um picador para reduzir o volume della e obter com esse serviço um pequeno lucro representado pela maio quantidade que se pode carregar no vagão e con Un vaga carregado con casca en canna pode levar 270 arobas o o mesmo 330. Esta differéc a convenienca qu

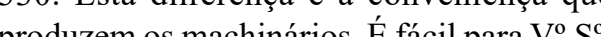
prompreen em que fornece um economia de um Ella mes come uma bon despeza de seu movin boa páne della pelo de adquir a machinari en podi sou obriga a pagar $30 \$ 000$ de inpostos. Pois bem, se a Respeitável Como So . reppresenta não quer allivir o inposto serei obrigado de reto allive o inposto casca sem machina, ficando assim sem imposto algum cousa que a Comarca me concede". (CÂMARA MUNICIPAL DE ARARAQUARA, 1928, cixas 29 e 30).

Entre 1930 e 1935, pelas mesmas razões foram fechadas: 1 fábrica de sapatos, 1 fábrica de camisas, 1 fábrica de roupas brancas, 1 fábrica de chapéus, 1 fábrica de brinquedos e 1 fábrica de instrumentos musicais. Os industriais, além de reclamarem sobre os elevados impostos que incidiam sobre a atividade de produção, também protestaram sobre os impostos de comercialização, especialmente aqueles cobrados sobre as atividades dos mascates e dos vendedores ambulantes, responsáveis pela venda de parte da produção local em municípios vizinhos. Esses impostos forçavam a elevação dos preços e, em consequência, uma queda nas vendas.

A partir de 1934 a questão teria ficado mais séria, dado que a vigilância dos fiscais municipais que, com muita frequência, autuavam e multavam os ambulantes da região, não se conduziam da mesma forma com relação a vendedores provenientes de outras regiões. Estes podiam, com relativa facilidade, penetrar na área, vender seus produtos a preços mais baixos e, dessa forma, concorrer com os produtos locais. (LORENZO, 1979)

Desde o início do século XX, os impostos que recaiam sobre as indústrias e profissões rte da receita municipal. Embora não se tenham condições para uma avaliação mais exata do significado das alterações no valor dos impostos, a diminuição do valor nominal, ocorrida a partir de 1927, somada às dificuldades decorrentes da crise na lavoura, sugere que o peso desses impostos foi muito elevado e, por essa razão, responsabilizado pelo fechamento de empresas. Contudo também foi possível constatar. por meio da correspondência analisada, a presença de um novo elemento, que até então não havia aparecido no desenvolvimento da indústria local a concorrência de produtos de outras regiões, principalmente da capital.

Dois movimentos interligados explicam em que medida a concorrência interferiu na indústria local Em primeiro lugar, a questão da "desproteção" que resultou do fim desse período de crescimento industrial, sob a dinâmica do capital cafeeiro, e expôs as empresas locais à concorrência regional e estadual. Em segundo lugar, a incapacidade de reação das empresas do local frente à questão da abertura do mercado nacional, que exigia das regiões onde houvesse alguma modalidade de indústria capacidade de reação ou potencial de transformação e crescimento "para fora" (CASTRO, 1971).

As empresas locais de pequeno e médio porte que até então se desenvolviam protegidas por custos diferenciais baixos, principalmente de transporte, e por terem a garantia dos restritos mercados locais, embora relativamente diversificada, estavam assentadas em bases muito frágeis. A partir do momento em que se desarticulou a sua principa razão de ser - o mercado local da economia cafeeira - a indústria que se desenvolvia na região entrou em decadência e não conseguiu manter seu ritmo anterior de crescimento.

Dentre as empresas voltadas ao consumo local, fundadas entre 1910 e 1930 , poucas sobreviveram. fábrica de móveis, olarias e alimentares. As três primeiras puderam sobreviver porque, além de não dependerem de grandes transformações técnicas, ainda permaneciam protegidas por custos diferenciais de transporte: o peso e o volume desses produtos elevariam consideravelmente os preços se eles tivessem de ser comprados em outras regiões. Quanto às empresas alimentares, sua sobrevivência deveu-se à existência de um mercado localizado e ainda à possibilidade de deterioração, caso de produtos como pães; doces, sorvetes tivessem que ser adquiridos em outras regiões.

No caso de Araraquara, foi possível constatar a existência de vários casos de "industriais" que se transformaram em comerciantes, passando a vender os mesmos produtos que antes produziam. Foi o caso de uma fábrica de sapatos e sapatões; uma fábrica de camisas e outra de roupas brancas; a fábrica de chapéus, (que em 1938 começou a comercializar Chapéus Ramenzoni, produzidos em Campinas); a fábrica de brinquedos; a fábrica de instrumentos musicais, que em 1939 transformou-se em um revendedor de sanfonas Scandali.

Ainda dentro deste grupo, a empresa que se revelou a mais importante, que existe até hoje que conseguiu transformar-se em grande empresa foi a fábrica de meias Lupo. Essa firma, muito embora em sua origem não se distinguisse das demais indústrias que surgiram na região entre 1910 e 1930, conseguiu sobreviver à crise de 1929, e, gradativamente foi se expandindo e se consolidando no mercado interno e externo. Até 1939, a Fábrica de Meias Lupo permaneceu como uma pequena empresa vendendo seu produto para a própria região. O primeiro período de expansão da empresa ocorreu em 1939, quando foi aumentada a produção e contratados 30 operários, em decorrência da aquisição de novas máquinas. Em consequência da Segunda Guerra Mundial, com a abertura de novos mercados externos, perdidos pelos países mais diretamente envolvidos com a guerra, a empresa pôde colocar seus produtos, inicialmente no Paraguai. A partir daí conseguiu consolida sua posição no mercado, vendendo inicialmente seu produto para alguns países latino-americanos: Argentina, Bolívia e Venezuela. Com relação ao mercado interno, apesar da concorrência acentuada, a empresa pôde ganhar sua fatia de mercado por produzir produtos sem similar no mercado nacional, com garantia de qualidade e com significativa inovação em gestão representada por um sistema de vendas, com representantes comerciais por todo erritório nacional.

Quanto às demais empresas, o pequeno tamanho da indústria e do mercado local e a precária capacidade de acumulação de capital não permitiu transformações técnicas que viabilizasse enfrentar a concorrência com produtos de fora. Por essas razões, a indústria local tendeu ao desaparecimento tão logo se desorganizou a economia cafeeira. E a região, no que diz respeito à produção de bens para o consumo, foi-se configurando como área de mercado para produtos vindos de fora (LORENZO, 1979).

\section{CONSIDERAÇÕES FINAIS}

A forte relação da indústria local com a atividade cafeeira pode ser vista sob vários aspectos. Em primeiro lugar, para o bom desempenho do café era necessário o aparecimento e a manutenção da atividade industrial. A pequena indústria atendia assim a necessidades para a acumulação na economia cafeeira. Segundo informações e correspondências encontradas nos arquivos municipais, o precoce incentivo ao desenvolvimento industrial não se devia a uma percepção de que a indústria, eventualmente, poderia vir a ser o elemento mais importante para a dinamização do processo de acumulação. Pelo contrario, a proteção e o incentivo à atividade industrial eram, nitidamente, formas de ampliação das oportunidades de inversão, tendo em vista, sempre o bom desempenho e maior eficiência da atividade cafeeira. Assim, o fazendeiro local, além da geração de emprego e renda e da sua contribuição para a formação do mercado local, teve elevada participação, na medida em que votou leis favoráveis ao crescimento industrial e estimulou o seu aparecimento. 
Em segundo lugar, embora não se possa contar com dados sobre a origem e volume do capital industrial na região, as indicações evidenciam que o capita cafeeiro foi fundamental para o crescimento industria na região. Como se observou por meio da narração da história de algumas empresas que se desenvolveram na região, o capital cafeeiro sempre se fazia presente. Em alguns casos, de forma direta, como em atividades de beneficiamento de café, fabricação do açúcar, pasteurização do leite e máquinas para a agricultura. Em outros casos, a presença do capital cafeeiro se manifestava indiretamente. $\mathrm{O}$ imigrante, ao investi seu capital em atividade industrial, tinha em mente o mercado criado pelo café; assim, indiretamente, o capital cafeeiro era responsável pela continuidade de sua evolução.

Por essas razões, o crescimento industrial que se desenvolveu na região até 1930 , apesar de te sido constituído por diversidade de segmentos e de estabelecimentos muito pequenos, pode sobreviver enquanto subsistiram as condições criadas pela expansão cafeeira.

Depois dos anos 30 os rumos da atividade industrial em todo o interior de São Paulo mudaram significativamente e estiveram altamente relacionados com a tendência à expansão concentração industrial nas proximidades da capital paulista, que contava com infraestrutura e ganhos de escala por concentração. Na história da indústria da região, os anos de 1930 caracterizaramse pela desorganização de parte das atividades anteriormente existentes. Tal fato está vinculado ao encerramento do período de crescimento com base no capital cafeeiro e na mudança no padrão de acumulação, ocorrida após 1929. Durante o período cafeeiro, o desenvolvimento de indústrias em áreas onde o café fazia surgir mercados urbanos configurava-se como área de influência no processo de acumulação. Após 1929 serão outros os elementos determinantes desse processo e que determinarão o crescimento da indústria na região.

Assim, frente à concorrência de empresas de maior porte que se firmavam no polo mais dinâmico de industrialização do estado de São
Paulo, as pequenas indústrias regionais tenderam a sucumbir. Sobraram algumas atividades, tipo alimentar, marcenarias e carpintarias ou fábricas de meias, as quais não dispunham na época de nenhum concorrente que lhe fizesse frente.

O caso da fabrica de meias Lupo foi uma exceção e deveu-se a uma "brecha" de mercado, permitida pelo polo mais dinâmico. Quer dizer, a fábrica de meias, possivelmente teria desaparecido, da mesma forma como desapareceram outras tantas atividades voltadas à produção de bens para o consumo, caso existissem na época outras empresas do mesmo ramo e de mesmas condições.

À medida que o elemento condutor do crescimento de São Paulo deixa de ser o capital cafeeiro e passa a ser o capital industrial, e que, consequentemente, $o$ processo de concentração industrial vai reafirmando sua presença especialmente no polo mais dinamico definindo as oportunidades do aparecimento e desenvolvimento de indústrias em áreas mais distantes desse polo. Nesse quadro não havia mais lugar para a continuidade do crescimento industrial na região.

\section{REFERÊNCIAS}

ANUÁRIO ESTATÍSTICO DE SÃO PAULO Movimento de população e estatística moral. 1900 1906, 1907, 1908, 1909, 1914, 1916. Repartição de Estatistica e Arquivo do Estado.

ANUÁRIO ESTATÍSTICO DE SÃO PAULO. Estatística econômica e financeira. Vol. II. 1904 1905,1906, 1907, 1908, 1909, 1914, 1916.

CÂMARA MUNICIPAL DE ARARAQUARA. Arquivos da Camara: correspondência dos prefeitos. 1908 a 1932

Atas das reuniões da Câmara municipa de Araraquara. Araraquara, São Paulo, 1908 a 1930.

Livros de leis do município de Araraquara. Araraquara, São Paulo, 1900 a 1930.
MUNICÍPIO DE SÃO CARLOS. Livros de registros de impostos sobre atividades: Indústrias e profissões. São Carlos, São Paulo, 1901 a 1941.

MUNICÍPIO DE ARARQUARA. Livros de registros de impostos sobre atividades: Indústrias e profissões. Araraquara, São Paulo, 1901 a 1941.

. Livro de registro de imposto de licença de funcionamento. 1947. Araraquara, São Paulo, 1942 a 1947

Livro de registo de pedidos de alvarás Araraquara, São Paulo, 1900 a 1930.

CANO, W. Raízes da concentração industria em São Paulo. São Paulo: Difel, 1977.

CASALECCHI, J. E. Da companhia industria agro-pastoril d'oeste de São Paulo a Cambuy Coffee Cotton Estates. Tese (Doutorado em Ciências Humanas) - Departamento de Filosofia e Ciências Humanas, Faculdade de Filosofia, Ciências Letras. Araraquara, 1973.

CORREA, A. M. M. A história social de Araraquara. Tese (Doutorado em Ciências Humanas) - Faculdade de Filosofia, Letras Ciências Humanas, USP, 1968.

CARDOSO DE MELLO, J. M. O capitalismo tardio: contribuição à revista crítica da formação e desenvolvimento da economia brasileira. Tese (Doutorado em Ciências Humanas) - Instituto de Filosofia e Ciências Humanas, UNICAMP, 1975.

CASTRO, A. B. "A herança regional no desenvolvimento brasileiro". In: (Org.) Sete ensaios sobre a economia brasileira. Rio de janeiro: Forense, 1971, p. 104

DAMIANO, O. Notícias históricas sobre os bondes de São Carlos. Trabalho mimeografado. São Carlos, 1954.
DEAN, W. A industrialização de São Paulo: 1880 - 1945. São Paulo: Difusão Europeia do Livro, 1971.

FURTADO, C. Formação econômica do Brasil. 6. ed. Rio de Janeiro: F.C.E., 1966

FRANÇA, A. M. Álbum de Araraquara. São Paulo: Ed. João Silveira, 1915

LORENZO, H. C. Origem e crescimento industrial na região Araraquara - São Carlos 1900 - 1970. Dissertação (Mestrado em Ciências Sociais) - Faculdade de Filosofia, Letras e Ciências Humanas, USP, 1979.

IBGE. Dados históricos dos censos. Instituto Brasileiros de Geografia e Estatística. 1996. Disponível em: < http:// www.ibge.gov.br/home/estatistica/populacao/ censohistorico/1872_1920.shtm $>$. Acesso em: 11 nov. 2015.

População nos censos demográficos de 1872/2010. Sinopse do censo demográfico 2010. Disponível em: $<$ http://www.censo2010.ibge.gov. $\mathrm{br} /$ sinopse/index.php?dados $=4 \& u f=00>$. Acesso em 11 nov. 2015.

PINA, H. A agroindústria açucareira e a sua legislação. São Paulo: APEC, 1972

SILVA, S. Expansão cafeeira e origem da ndústria no Brasil. São Paulo: Editora Alfa Ômega, 1976

SZMERECSÁNYI, T. Apontamentos para uma história econômica do Brasil no período 1920-50. Ensaios, v. 1, n. 1, p. $3-42$, jun. 1980

VILLELA, A. V.; SUZIGAN, W. Política do governo e crescimento da economia brasileira: 1889 - 1945. Rio de Janeiro: IPEA/INPES, 19973. 